\title{
Adherence to Medical Cannabis Among Licensed Patients in Israel
}

\author{
Yuval Zolotov, ${ }^{1,2, *}$ Yehuda Baruch, ${ }^{3}$ Haim Reuveni, ${ }^{4}$ and Racheli Magnezi ${ }^{1}$
}

\begin{abstract}
Objectives: To evaluate adherence among Israeli patients who are licensed to use medical cannabis and to identify factors associated with adherence to medical cannabis.

Methods: Ninety-five novice licensed patients were interviewed for this cross-sectional study. The questionnaire measured demographics, the perceived patient-physician relationship, and the level of patients' active involvement in their healthcare. In addition, patients were queried about adverse effect(s) and about their overall satisfaction from this medical treatment.

Results: Eighty percent $(n=76)$ has been identified as adherent to medical cannabis use. Variables found associated with adherence were "country of origin" (immigrant status), "type of illness" (cancer vs. non-cancer), and "experiencing adverse effect(s)." Three predictors of adherence were found significant in a logistic regression model: "type of illness" (odds ratio [OR] 0.101), patient-physician relationship (OR 1.406), and level of patient activation (OR 1.132). $71.5 \%$ rated themselves being "completely satisfied" or "satisfied" from medical cannabis use. Conclusions: Our findings show a relatively high adherence rate for medical cannabis, as well as relative safety and high satisfaction among licensed patients. Additionally indicated is the need to develop and implement standardized education about this evolving field —-to both patients and physicians.
\end{abstract}

Key words: behavior; medical therapy; public policy; regulation

\section{Introduction}

The use of medical cannabis is steadily increasing, both in Israel and globally, ${ }^{1-3}$ and the potential of cannabis as a therapeutic agent has been gaining both interest and acknowledgment. ${ }^{4,5}$ Nevertheless, although cannabis has been used for medical purposes throughout history, ${ }^{6,7}$ Western medicine generally does not accept it as a legitimate therapeutic treatment and social and legal barriers prevent adequate research in this field. ${ }^{4,8,9}$

The Israeli regulatory program of medical cannabis has changed through the years and is managed by a Medical Cannabis Unit of the Israeli Ministry of Health $(\mathrm{MOH})$. Licenses are issued upon approval of a medi- cal recommendation by a specialist, whose specialty is relevant to the medical problem for which medical cannabis is requested. The estimated number of patients is currently 22,000 , and licenses are generally granted as a last resort for patients whose symptoms have not been alleviated by traditional medications and treatments. ${ }^{10}$ Nevertheless, preliminary data from $\mathrm{MOH}$ indicate that a subset of patients are in fact not using medical cannabis despite being licensed, namely not adhering to this treatment regimen.

Adherence to (or compliance with) a medication regimen has been defined by the WHO as "the extent to which patients take medications as prescribed by

\footnotetext{
${ }^{1}$ Public Health and Health Systems Management Program, Department of Management, Bar Ilan University, Ramat-Gan, Israel.

${ }^{2} \mathrm{School}$ of Public Health, University of Haifa, Haifa, Israel.

${ }^{3}$ Gertner Institute for Epidemiology and Health Policy Research, Sheba Medical Center, Ramat-Gan, Israel.

${ }^{4}$ Department of Health Systems Management, Ben-Gurion University of the Negev, Be'er Sheva, Israel.
}

*Address correspondence to: Yuval Zolotov, MHA, Public Health and Health Systems Management Program, Department of Management, Bar Ilan University, Ramat-Gan 52621, Israel, E-mail: tubyzolo@gmail.com

(c) Yuval Zolotov et al. 2016; Published by Mary Ann Liebert, Inc. This Open Access article is distributed under the terms of the Creative Commons License (http://creativecommons.org/licenses/by/4.0), which permits unrestricted use, distribution, and reproduction in any medium, provided the original work is properly credited. 
their healthcare providers." 11 Nonadherence affects patient outcomes, including quality of life, as well as adding unnecessary costs to the health system. ${ }^{12}$ Barriers to adherence have been largely categorized into three types: (1) barriers related specifically to the patient (e.g., economic status, lifestyle, anxiety or other emotional factors); (2) barriers associated with the healthcare provider (mainly patient-physician interactions); and (3) barriers related to the health system (e.g., regulations on price and accessibility). ${ }^{13}$

Accumulating scientific evidence suggests that cannabis may potentially be a promising therapy for different patient populations, including pain, ${ }^{14-17}$ oncology, ${ }^{18,19}$ HIV, ${ }^{20}$ and Crohn's disease. ${ }^{21}$ Amplified by public demand and political pressures, this has led to laws and regulations that hitherto permit the legal use of medical cannabis in 23 states in the United States and in several other countries worldwide, including Israel.,

Across the different medical cannabis regulations of healthcare systems around the world, physicians are functioning as gatekeepers who approve (or disapprove) the use of medical cannabis, either directly as in the United States and in the new regulatory system of Canada ${ }^{1,22}$ or by signing a document that entails further authorization by health authorities, as in Israel and in the old Canadian system. ${ }^{18,23,24}$ While few studies, mainly from the United States, have found physicians to be either skeptical or negative toward medical cannabis, ${ }^{25-31}$ a recent study has found Israeli physicians to be, in contrast, partially positive. ${ }^{32}$ In addition, an international poll conducted on the website of the New England Journal of Medicine has found vast support for medical cannabis use. ${ }^{33}$

The patient-physician relationship is an important factor in medical care and it affects positive treatment outcomes, including patient satisfaction, adherence to therapy, and even efficacy. ${ }^{34}$ Better patient-physician communication was found to have a crucial effect on adherence to medical treatments. ${ }^{35}$

In recent years, patients are empowered to participate in their medical care. ${ }^{36-38}$ The Patient Activation Measure (PAM) was developed ${ }^{39}$ to quantify the level of knowledge, experience, responsibility, and confidence that a patient has with regard to managing his or her health situation. PAM has been frequently used in different settings, ${ }^{40}$ and higher levels of this measure were found to be associated with different treatment outcomes, including better adherence. ${ }^{36,40,41}$

Despite both the utmost importance of adherence to medical regimens and the worldwide increase in med- ical cannabis use, to our knowledge no data about adherence to medical cannabis have been so far published. The study objectives were (1) to evaluate the adherence rate among patients who are licensed to use medical cannabis in Israel; and (2) to identify factors that are associated with adherence to medical cannabis. Based on previous studies, we hypothesized that the patientphysician relationship, as well as the level of patient activation, will be associated with better adherence.

\section{Methods}

\section{Participants}

The population of this cross-sectional study was patients aged 18 years or older who were issued a novel license to use medical cannabis between May and September $2013(n=461)$. Two hundred and forty $(52 \%)$ gave an initial consent, on their license application, to be contacted for research purposes. Of those, 95 (40\%) patients participated in the study and answered the questionnaire through telephone interviews. The remaining 145 patients were not interviewed due to the following reasons: wrong contact details or disconnected phone numbers $(17 \%, n=41)$; no answer to recurrent calls in three different days at three different times of the day $(16.2 \%, n=39)$; deceased $(11.2 \%$, $n=27)$; refused to participate $(8.3 \%, n=20)$; or sick and unable to communicate $(7.5 \%, n=18)$. All participants were contacted within 5-8 weeks of being initially licensed to use medical cannabis.

\section{Ethical statement}

The institutional review board was granted to receive contact details of licensed patients who had given their authorization to be contacted for research purposes. Informed consent was obtained orally at the beginning of the interview, and all personal details were kept separately from patients' responses.

\section{Measures}

The questionnaire included four sections and was reviewed by five physicians with extensive experience in medical cannabis for face and content validity and for overall reliability. The first section of the questionnaire included demographic information-gender, age, country of birth (immigrant status), education, and income level-as well as questions about tobacco use and the primary type of illness (for which medical cannabis license was granted).

In the second section, we used the PAM, a validated questionnaire developed by Hibbard et al., ${ }^{39}$ to quantify 
patients' level of participation in their healthcare. PAM is scored on a theoretical $0-100$ scale, which is also categorized to four levels of activation. ${ }^{40}$ This 13 -item scale has been previously translated and validated in Hebrew, ${ }^{42}$ and internal consistency of this measure in the current study, calculated using the Cronbach's alpha test, was $\alpha=0.826$.

In the third section, we adopted the Patient-Doctor Relationship Questionnaire (PDRQ-9) ${ }^{43}$ to evaluate how patients perceived the relationship between them and the physician who had provided them the medical recommendation (that is required before medical cannabis licensure). The PDRQ-9 is a valid and reliable measure that was developed out of the Helping Alliance Questionnaire. ${ }^{44}$ Validation of the Hebrew version was achieved by forward and backward translations made by two independent bilingual translators. Few of the questions were slightly revised to adapt the questionnaire for this study. For instance, the item "I can talk freely with my healthcare provider" was changed to "I can talk freely with my physician about medical cannabis." Similarly, the item "My primary care provider and I agree on the nature of my medical symptoms" was revised to "My physician and I agree on the nature of my medical symptoms, for which I am licensed to use medical cannabis." The internal consistency of this measure in the current study, calculated using the Cronbach's alpha test, was $\alpha=0.803$.

The fourth section measured adherence and nonadherence to medical cannabis use by asking directly "are you currently using medical cannabis?" Nonadhering patients were asked whether they have ever used medical cannabis after being issued a license, and if so for how long and by which way of administration. Adhering patients were questioned about patterns of use (dosage and way of administration). Last, all participants who were using medical cannabis at the time of the interview, or beforehand, were asked to specify if they have ever experienced adverse effect(s) resulting from medical cannabis and were asked to subjectively rate their satisfaction from the medical effect(s) of medical cannabis use (on a 5-point scale from "completely unsatisfied" to "completely satisfied").

\section{Statistical analyses}

Chi-square tests of independence and Wilcoxon signed-rank tests were used to examine the association between the different independent variables and adherence. T tests were used to compare means of PAM and PDRQ between adhering and nonadhering patients. A binary logistic regression model was used to identify potential predictors of adherence. Odds ratios with 95\% confidence intervals were calculated for potential predictors. All statistical analyses were performed using SPSS statistical software, version 20.

\section{Results}

Sample characteristics

Table 1 presents demographic variables, as well as tobacco use and type of illness, stratified to "adherent" $(80 \%, n=76)$ and "nonadherent" $(20 \%, n=19)$. Native Israelis were more adherent than immigrants $\left[\chi^{2}(1)=\right.$ 3.8, $p=0.05$ ], who were mainly from former USSR $(18.9 \%, n=18)$ and North Africa or Iraq $(7.4 \%, n=7)$. In addition, cancer patients were less adherent to medical cannabis use than those with other sickness $\left[\chi^{2}(2)=11.8\right.$, $p<0.01]$.

The average scores of nonadhering patients to both PAM and PDRQ were significantly lower $(p<0.001)$ than the scores of adhering patients $(48.9 \pm 12.3$ vs. $62.6 \pm 10.5$ and $30.3 \pm 4.6$ vs. $35.7 \pm 3.6$, respectively).

Table 2 shows the logistic regression model of predicting adherence. With demographic variables controlled, three variables were found to be significantly predicting adherence: type of illness: cancer versus

Table 1. Characteristics of the Study Sample $(N=95)$

\begin{tabular}{|c|c|c|}
\hline Variable & Adherent, $N(\%)$ & Nonadherent, $N(\%)$ \\
\hline \multicolumn{3}{|c|}{ Gender, $\chi^{2}(1)=0.412, p=0.521$} \\
\hline Female & $26(34.2)$ & $8(42.1)$ \\
\hline Male & $50(65.8)$ & $11(57.9)$ \\
\hline \multicolumn{3}{|c|}{ Age, years, $\chi^{2}(3)=3.490, p=0.322$} \\
\hline $18-30$ & $12(16.4)$ & $2(10.5)$ \\
\hline $31-45$ & $20(27.4)$ & $3(15.8)$ \\
\hline $46-60$ & $22(30.1)$ & $5(26.3)$ \\
\hline$>60$ & $19(26.1)$ & $9(47.4)$ \\
\hline \multicolumn{3}{|c|}{ Country of origin, $\chi^{2}(1)=3.817, p=0.051$} \\
\hline Israel & $54(71.1)$ & 9 (47.4) \\
\hline Other & $22(28.9)$ & $10(52.7)$ \\
\hline \multicolumn{3}{|c|}{ Education, years, $\chi^{2}(3)=0.251, p=0.472$} \\
\hline$<12$ & $17(22.4)$ & $6(31.6)$ \\
\hline 12 & $32(42.1)$ & $9(47.4)$ \\
\hline $13-15$ & 15 (19.7) & $1(5.3)$ \\
\hline$>16$ & $12(15.8)$ & $3(15.8)$ \\
\hline \multicolumn{3}{|c|}{ Income, $\chi^{2}(2)=1.398, p=0.497$} \\
\hline Above average & $11(14.5)$ & $1(5.3)$ \\
\hline Average & $18(23.7)$ & $4(21.1)$ \\
\hline Below average & $47(61.8)$ & $14(73.7)$ \\
\hline \multicolumn{3}{|c|}{ Tobacco use, $\chi^{2}(1)=2.429, p=0.119$} \\
\hline Yes & $35(46.1)$ & $5(26.3)$ \\
\hline No & $41(53.9)$ & $14(73.7)$ \\
\hline \multicolumn{3}{|c|}{ Type of illness, $\chi^{2}(2)=11.820, p=0.003$} \\
\hline Cancer & $24(31.6)$ & 14 (73.7) \\
\hline Chronic pain & $42(55.3)$ & $3(15.8)$ \\
\hline Other & $10(13.2)$ & $2(10.5)$ \\
\hline
\end{tabular}


Table 2. Logistic Regression Model Predicting Adherence to Medical Cannabis

\begin{tabular}{lccl}
\hline Variable & Odds ratio & $95 \% \mathrm{Cl}$ & $p$ \\
\hline Age & 1.034 & $0.978-1.093$ & 0.237 \\
Gender & 5.705 & $0.815-39.953$ & 0.079 \\
Country of origin & 3.365 & $0.396-28.604$ & 0.266 \\
Education & 1.296 & $0.857-1.96$ & 0.22 \\
Income & 3.762 & $0.357-39.597$ & 0.27 \\
Type of illness & 0.101 & $0.012-0.823$ & 0.032 \\
PAM & 1.132 & $1.03-1.244$ & 0.01 \\
PDRQ-9 & 1.406 & $1.112-1.777$ & 0.004 \\
\hline
\end{tabular}

95\% Cl, 95\% confidence interval; PAM, Patient Activation Measure PDRQ-9, Patient-Doctor Relationship Questionnaire.

noncancer $(p<0.05)$ and scores of both PAM $(p<0.01)$ and PDRQ $(p<0.01)$.

\section{Patterns of use}

Of the adhering patients $(n=76)$, most were using medical cannabis by smoking, either as the sole way of administration $(61.8 \%, n=47)$ or in addition to edibles $(4.2 \%, n=4)$, vaporizer $(2.6 \%, n=2)$, or ointment $(2.6 \%, n=2)$. Other adhering patients used medical cannabis only with vaporizer $(3.9 \%, n=3)$, as an ointment $(15.8 \%, n=15)$, or as an edible $(3.9 \%, n=3)$. The monthly dosage that patients were authorized to use was $20 \mathrm{~g}$ for most patients $(93.4 \%, n=71)$ and $30 \mathrm{~g}$ to all others $(6.6 \%, n=5)$.

Of the nonadhering patients $(n=19), 63.1 \%(n=12)$ reported to have started using medical cannabis, but quit after 2 weeks on average (median: 10 days, range: 1-6 weeks). These patients reported to have used medical cannabis by smoking $(36.8 \%, n=7)$, as an ointment $(21 \%, n=4)$ or as an edible $(0.5 \%, n=1)$.

\section{Adverse effect and patients' satisfaction}

Of the 88 patients who have either been found adherent $(n=76)$ or who have experienced medical cannabis before quitting $(n=12), 30.7 \%(n=27)$ reported experiencing one adverse effect or more due to medical cannabis use. Experiencing adverse effect(s) was more common among nonadhering patients $(58.3 \%, n=7)$ than among adhering patients $(26.3 \%, n=20)$, and this association was found significant $\left[\chi^{2}(1)=5, p<0.05\right]$. The most common adverse effects were dizziness $(17 \%, n=15)$, dehydrated mouth $(11.3 \%, n=10)$, fatigue $(6.8 \%, n=6)$, mild anxiety $(5.6 \%, n=5)$, and feeling "weird" $(5.6 \%, n=5)$.

Most patients were either "completely satisfied" $(43.1 \%, n=38)$ or "satisfied" $(28.4 \%, n=25)$ from the use of medical cannabis; 10 patients $(11.3 \%)$ were "somewhat satisfied;" 10 (11.3\%) were "not so satisfied," and 5 (5.6\%) were "completely unsatisfied."

\section{Discussion}

This study draws attention to adherence to medical cannabis, which has so far not been examined. The adherence rate we found is higher than adherence rates reported for other medical treatments in previous studies, ${ }^{45-47}$ and we suggest that this may be partially explained by the fact that licenses are only granted to patients who have gone through prior treatment regimens, thus already proving themselves as adherent patients. Other factors that could explain this relatively high adherence rate are the relative safety of medical cannabis (as demonstrated by patients' reports on adverse effects) and the overall high satisfaction that patients expressed from using medical cannabis.

While comparing the rates of adherence to medical cannabis to those of other treatments, one should note that the essence of adherence is profoundly different across different treatment regimens and different patient populations. ${ }^{13}$ Medical cannabis is essentially dissimilar to other medical treatments in many aspects. For instance, unlike other prescriptions, medical cannabis is usually administrated by smoking, ${ }^{48}$ and patients are usually not guided by physicians about the desired dosage and other use patterns. ${ }^{27}$

The country of birth (immigrant status) was the only demographic variable that was found associated with adherence, so that immigrants were more likely to be nonadherent, and this finding is consistent with other studies from Israel that reported higher rates of nonadherence among immigrants. ${ }^{49,50}$ It is plausible that language barriers and cultural gaps contributed to this lower adherence rate, as patients from different cultural backgrounds differ in their health behavior and their health beliefs, ${ }^{51}$ which in turn may affect adherence.

Echoing a meta-analysis that found an association between adherence and the (perceived) disease severity, ${ }^{52}$ we found cancer patients to be at greater risk of nonadherence than noncancer patients. While the majority of the noncancer patients were chronic pain patients, who probably have considerable experience in using opioids or other so-called narcotics, cancer patients may have less familiarity with such substances and therefore may be more wary of the stigmatization of using such a drug.

As we hypothesized, patient activation was indeed associated with adherence to medical cannabis use. This is consistent with previous studies which found that patient activation predicted better health outcomes and better health behaviors. ${ }^{38,40,41}$ Similarly, the patientphysician relationship was associated with adherence, 
which resembles findings of previous studies, ${ }^{34,53-55}$ and might imply a positive correlation between (perceived) patient-physician relationship and adherence.

Despite the inherent limitations of the crosssectional study design, this study provides primary, yet valuable, data about the convoluted topic of our study. Our main limitation is the small sample size $(n=95)$. However, this sample may be in fact representative, as gender and age distribution of the study population is similar to that of medical cannabis patients in Israel, as derived from official data of the Israeli $\mathrm{MOH}$. In addition, adherence to medical treatments in general, and to medical cannabis specifically, is a complex phenomenon that incorporates biological factors, as well as behavioral, psychological, social, cultural, and others. Thus, our study design might have partially failed to capture its full complexity, which future studies should target with varied strategies. Last, our study is based on self-reports, which could be somewhat limited and biased. However, most of the items used in this study were validated measurements.

\section{Conclusion}

Our findings show a relatively high adherence rate for medical cannabis, as well as relative safety and high satisfaction among licensed patients. Thus, medical cannabis seems to be a favorable treatment option, and physicians and regulators should enable access to eligible patients while finding the sensitive balance between the existing scientific evidence and patients' rights and preferences.

\section{Practice implications}

Our findings point to the importance of patients' empowerment and activation, which can be mainly strengthened through education. Thus, it would be reasonable to consider the implementation of standardized patient education for medical cannabis use and to impose this education process as mandatory to all novice medical cannabis patients. As suggested by our findings, special care could be designed for cancer patients and immigrant patients, to minimize the risk of nonadherence. The patient-physician relationship was spotted as an important factor, and we suggest that this interaction could and should be improved. Possible ways of achieving this is by building a bonafide relationship before the discussion about medical cannabis and by providing more education about medical cannabis to physicians and other healthcare providers.
Last, technological arrangements could be made to facilitate "real-time" data collection from licensed medical cannabis suppliers, to enable a more systematic surveillance of medical cannabis use, and specifically adherence to this treatment. With the goal of minimizing nonadherence and improving clinical care, nonadhering patients could be thus spotted and offered to join an intervention.

\section{Author Disclosure Statement}

No competing financial interests exist.

\section{References}

1. Fischer B, Kuganesan S, Room R. "Medical Marijuana" programs-the better "third way" or sneaky side-door for cannabis control reform? Observations from Canada. Int J Drug Policy. 2015;26:15-19. doi:10.1016/ j.drugpo.2014.09.007.

2. Belle-Isle L, Walsh Z, Callaway R, et al. Barriers to access for Canadians who use cannabis for therapeutic purposes. Int J Drug Policy. 2014. doi:10.1016/j.drugpo.2014.02.009.

3. Sznitman SR, Zolotov Y. Cannabis for therapeutic purposes and public health and safety: a systematic and critical review. Int J Drug Policy. 2015;26:20-29.

4. Bostwick JM. Blurred boundaries: the therapeutics and politics of medical marijuana. Mayo Clin Proc. 2012;87:172-186.

5. Carter GT, Javaher SP, Nguyen MH, et al. Re-branding cannabis: the next generation of chronic pain medicine? Pain Manag. 2015;5:13-21.

6. Zuardi AW. History of cannabis as a medicine: a review. Rev Bras Psiquiatr. 2006;28:153-157.

7. Kalant $\mathrm{H}$. Medicinal use of cannabis - history and current status. Pain Res Manag. 2001;6:80-91.

8. Philipsen N, Butler RD, Simon-Waterman C, et al. Medical marijuana: a primer on ethics, evidence, and politics. J Nurse Pract. 2014;10:633-640.

9. Rubens M. Political and medical views on medical marijuana and its future. Soc Work Public Health. 2014;29:121-131.

10. Sznitman SR, Lewis N. Is cannabis an illicit drug or a medicine? A quantitative framing analysis of Israeli newspaper coverage. Int J Drug Policy. 2015. doi:10.1016/j.drugpo.2015.01.010.

11. Sabaté $E$, ed. Adherence to long-term therapies evidence for action. World Health Organization: Geneva, 2003. http://search.ebscohost.com/ login.aspx?direct=true $\&$ scope $=$ site $\& d b=$ nlebk $\& d b=$ labk $\& A N=114059$ (accessed February 26, 2014).

12. Cutler DM, Everett W. Thinking outside the pillbox-medication adherence as a priority for health care reform. N Engl J Med. 2010;362:1553-1555.

13. Osterberg L, Blaschke T. Adherence to medication. N Engl J Med. 2005;353:487-497.

14. Lucas P. Cannabis as an adjunct to or substitute for opiates in the treatment of chronic pain. J Psychoactive Drugs. 2012;44:125-133.

15. McQuay HJ. More evidence cannabis can help in neuropathic pain. Can Med Assoc J. 2010;182:1494-1495.

16. Ware MA, Wang T, Shapiro S, et al. Smoked cannabis for chronic neuropathic pain: a randomized controlled trial. CMAJ. 2010;182:E694-E701.

17. Wilsey B, Marcotte $T$, Deutsch R, et al. Low-dose vaporized cannabis significantly improves neuropathic pain. J Pain. 2013;14:136-148.

18. Bar-Sela G, Vorobeichik M, Drawsheh S, et al. The medical necessity for medicinal cannabis: prospective, observational study evaluating the treatment in cancer patients on supportive or palliative care. Evid Based Complement Alternat Med. 2013;2013:510392.

19. Machado Rocha FC, Stéfano SC, De Cássia Haiek R, et al. Therapeutic use of Cannabis sativa on chemotherapy-induced nausea and vomiting among cancer patients: systematic review and meta-analysis. Eur J Cancer Care (Engl). 2008;17:431-443.

20. Abrams DI, Hilton JF, Leiser RJ, et al. Short-term effects of cannabinoids in patients with HIV-1 infection: a randomized, placebo-controlled clinical trial. Ann Intern Med. 2003;139:258-266. 
21. Naftali T, Bar-Lev Schleider L, Dotan I, et al. Cannabis induces a clinical response in patients with Crohn's disease: a prospective placebocontrolled study. Clin Gastroenterol Hepatol. 2013;11:1276-1280.e1.

22. Aggarwal SK, Carter GT, Sullivan MD, et al. Medicinal use of cannabis in the United States: historical perspectives, current trends, and future directions. J Opioid Manag. 2009;5:153-168. http://www.oregon.gov/ pharmacy/imports/marijuana/staffinfo/medicinaluseofcannabisintheus .pdf. Accessed November 23, 2013.

23. Eggertson L. New medical marijuana regulations shift onus to doctors to prescribe. Can Med Assoc J. 2013;185:E553-E554

24. Shelef A, Mashiah M, Schumacher I, et al. Medical grade cannabis (MGC): regulation mechanisms, the present situation around the world and in Israel [in Hebrew]. Harefuah. 2011;150:913-917, 935, 934.

25. Charuvastra A, Friedmann PD, Stein MD. Physician attitudes regarding the prescription of medical marijuana. J Addict Dis. 2005;24:87-93.

26. Kondrad E, Reid A. Colorado family physicians' attitudes toward medical marijuana. J Am Board Fam Med. 2013;26:52-60.

27. Fletcher J. Marijuana is not a prescription medicine. Can Med Assoc J. 2013;185:369.

28. Thompson JW, Koenen MA. Physicians as gatekeepers in the use of medical marijuana. J Am Acad Psychiatry Law. 2011;39:460-464.

29. Wilkinson ST, D'Souza DC. Problems with the medicalization of marijuana. JAMA. 2014;311:2377-2378.

30. Saper CB. Up in smoke: a neurologist's approach to "medical marijuana." Ann Neurol. 2015;77:13-14.

31. Hill KP. Medical marijuana: more questions than answers. J Psychiatr Pract. 2014;20:389-391.

32. Ebert T, Zolotov Y, Eliav S, et al. Assessment of Israeli physicians' knowledge, experience and attitudes towards medical cannabis: a pilot study. Isr Med Assoc J. 2015;17:437-441.

33. Adler JN, Colbert JA. Medicinal use of marijuana-polling results. N Engl Med. 2013;368:e30.

34. Haskard Zolnierek KB, DiMatteo MR. Physician communication and patient adherence to treatment: a meta-analysis. Med Care. 2009;47: 826-834.

35. Joosten EAG, DeFuentes-Merillas $\mathrm{L}$, de Weert GH, et al. Systematic review of the effects of shared decision-making on patient satisfaction, treatment adherence and health status. Psychother Psychosom. 2008;77:219226.

36. Bodenheimer $\mathrm{T}$, Lorig $\mathrm{K}$, Holman $\mathrm{H}$, et al. Patient self-management of chronic disease in primary care. JAMA. 2002;288:2469-2475.

37. Holman H, Lorig K. Patient self-management: a key to effectiveness and efficiency in care of chronic disease. Public Health Rep. 2004; 119:239.

38. Rask KJ, Ziemer DC, Kohler SA, et al. Patient activation is associated with healthy behaviors and ease in managing diabetes in an indigent population. Diabetes Educ. 2009;35:622-630.

39. Hibbard JH, Stockard J, Mahoney ER, et al. Development of the patient activation measure (PAM): conceptualizing and measuring activation in patients and consumers. Health Serv Res. 2004;39(4 Pt 1): 1005-1026.

40. Greene J, Hibbard JH. Why does patient activation matter? An examination of the relationships between patient activation and health-related outcomes. J Gen Intern Med. 2012;27:520-526.

41. Marshall R, Beach MC, Saha S, et al. Patient activation and improved outcomes in HIV-infected patients. J Gen Intern Med. 2013;28:668-674.

42. Magnezi R, Glasser S. Psychometric properties of the Hebrew translation of the patient activation measure (PAM-13). Brucki S, ed. PLoS One. 2014;9:e113391.
43. Van der Feltz-Cornelis CM, Van Oppen P, Van Marwijk HW, et al. A patientdoctor relationship questionnaire (PDRQ-9) in primary care: development and psychometric evaluation. Gen Hosp Psychiatry. 2004;26:115-120.

44. Luborsky L, Barber JP, Siqueland $L$, et al. The revised Helping Alliance questionnaire (HAq-II): psychometric properties. J Psychother Pract Res. 1996;5:260.

45. Cramer JA. A systematic review of adherence with medications for diabetes. Diabetes Care. 2004;27:1218-1224.

46. DiMatteo MR. Variations in patients' adherence to medical recommendations: a quantitative review of 50 years or research. Med Care. 2004:42:200-209.

47. Fischer MA, Stedman MR, Lii J, et al. Primary medication non-adherence: analysis of 195,930 electronic prescriptions. J Gen Intern Med. 2010;25:284-290.

48. Kalant H. Smoked marijuana as medicine: not much future. Clin Pharmacol Ther. 2008;83:517-519.

49. Vinker S, Shani M, Baevsky T, et al. Adherence with statins over 8 years in a usual care setting. Am J Manag Care. 2008;14:388-392.

50. Wilf-Miron R, Peled R, Yaari E, et al. The association between sociodemographic characteristics and adherence to breast and colorectal cancer screening: analysis of large sub populations. BMC Cancer. 2011;11:376.

51. Kaplan RC, Bhalodkar NC, Brown EJ, et al. Race, ethnicity, and sociocultural characteristics predict noncompliance with lipid-lowering medications. Prev Med. 2004;39:1249-1255.

52. DiMatteo MR, Haskard KB, Williams SL. Health beliefs, disease severity and patient adherence: a meta-analysis. Med Care. 2007;45:521-528.

53. Arbuthnott A, Sharpe D. The effect of physician-patient collaboration on patient adherence in non-psychiatric medicine. Patient Educ Couns. 2009;77:60-67.

54. Butow $P$, Sharpe $L$. The impact of communication on adherence in pain management. Pain. 2013.

55. Thompson L, McCabe R. The effect of clinician-patient alliance and communication on treatment adherence in mental health care: a systematic review. BMC Psychiatry. 2012;12:87.

Cite this article as: Zolotov Y, Baruch Y, Reuveni H, Magnezi R (2016) Adherence to medical cannabis among licensed patients in Israel, Cannabis and Cannabinoid Research 1:1, 16-21, DOI: 10.1089/ can.2015.0003.

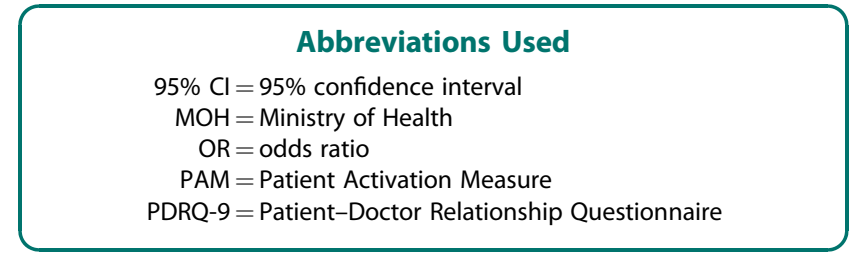

Publish in Cannabis and Cannabinoid Research

Cannabis and

Cannabinoid

Research
- Immediate, unrestricted online access

- Rigorous peer review

- Compliance with open access mandates

- Authors retain copyright

- Highly indexed

- Targeted email marketing

liebertpub.com/can 